\title{
"Let us salute one of our kind." How academic obituaries consecrate research biographies
}

\author{
Julian Hamann, (hamann@uni-bonn.de) \\ Forum Internationale Wissenschaft, University of Bonn, Germany
}

\begin{abstract}
Academics undertake considerable efforts in order to define positions for themselves and for their peers that are meaningful and convey who they "are". The current article examines how academics manage the practical task of making sense of one another by analyzing the way in which academic obituaries beget and consecrate research biographies. A qualitative analysis of 216 obituaries published in academic journals from the United States, United Kingdom, and Germany, in physics, history, and sociology, and from the 1960s to the 2000s reveals (e)valuative practices that consecrate academic subjects. The results demonstrate how obituaries: (1) categorize academic subjects by positioning them within spheres of academic knowledge and institutional posts, and (2) legitimize academic subjects by applying biographical narratives of talent and merit. This biographical (e)valuation evokes naturally talented, highly devoted academic subjects with coherent research profiles, and omits both biographical hurdles and the decedent's gender and class. The insights shed light on underlying academic virtues and values.
\end{abstract}

\section{Keywords}

Academic obituaries; Evaluation; Academic careers; Research biographies; Narratives; Positioning 


\section{Introduction}

Academia is a relational undertaking. Researchers cannot define who they "are" by themselves; rather, scholars are constantly evaluated, classified, and positioned by their peers. Given this relentless collegial gaze, it is not surprising that researchers continuously work on forging a meaningful biography from institutional affiliations, publications, research projects, and various formal and informal memberships. Academics undertake this biographical work in an attempt to create coherent, meaningful positions for themselves in the relational interplay of ascriptions and classifications. The current research improves the scholarly understanding of how academics manage the practical and - literally - existential task of making sense of one another via consecration.

Academic obituaries provide rich empirical material for this purpose. These documents evaluate researchers' efforts to forge a meaningful biography. To this end, obituaries consolidate the distinct, sometimes accidental and incoherent, stations and achievements of an academic life course into a linear trajectory. The resulting biographical artifacts are coherent depictions of legitimate research careers. The way in which obituaries construct biographies provides insight into the customary rules that their authors must follow in order to consecrate the decedents. These rules are not formally defined, but rather are informally created, learned, and reinforced within academic practice (Lamont, 2009). Thus, the specific way in which obituaries (e)valuate research biographies is determined by more than just personal recollections - authors are agents of the customary rules that must be followed in acts of (e)valuation (Bourdieu, 1988). Guided by these informal and taken-for-granted rules, depictions of academic lives therefore represent and reproduce a professional ethos as well as a system of academic virtues and values.

Based on a sample of 216 obituaries, published in academic publications from the United States (U.S.), United Kingdom (UK), and Germany, in physics, history, and 
These are proofs of the final publication that is available at Elsevier via Poetics, doi:10.1016/j.poetic.2016.02.005,

http://www.sciencedirect.com/science/article/pii/S0304422X16000164

sociology, and from the 1960 s to the 2000 s, this study examines two general aspects of the consecration of academic lives: the categorization of biographies in a relational and fluid interplay of positioning and ascriptions, and the legitimizing narration of life courses as a meaningful, comprehensive sequence. The resulting insights go beyond the genre of obituaries - they are relevant to questions of academic careers, research biographies, identities, and professional values. As the following section demonstrates, the study of obituaries (Fowler, 2005) generates findings about the consecration of academic life courses that contribute novel insights to the research fields of academic (e)valuation (Lamont, 2012) and academic positioning practices and narratives (Angermuller, 2013).

\section{Academic (e)valuation and positioning, and the study of academic obituaries}

Questions of academic evaluation, including inquiries into both the values and virtues underlying this evaluation and the positions and classifications it engenders, have yielded a broad body of literature. A first strand of this literature has paid tribute to the central importance of evaluation in academia. While numeric measures, focused mainly on publication or citation counts, are a more recent approach, judgment by peers is a longstanding form of determining quality and achievements (Zuckerman \& Merton, 1971). Research on peer review conducted for academic journals, funding agencies, or the evaluation of potential faculty members is primarily concerned with the reliability of such judgments (Bornmann \& Daniel, 2005; Sonnert, 1995), their potentially dysfunctional effects (Hamann, 2016; Lee \& Harley, 1998; Sandström \& Hällsten, 2008), differences in the definition of merit (Guetzkow, Lamont \& Mallard, 2004; Lewis, 1998; Tsay et al., 2003), and how reviewers reach a consensus about "quality" (Bakanic, McPhail \& Simon, 1987;

Hirschauer, 2010; Lamont, 2009). 
These are proofs of the final publication that is available at Elsevier via

Poetics, doi:10.1016/j.poetic.2016.02.005,

http://www.sciencedirect.com/science/article/pii/S0304422X16000164

A second strand of literature is concerned with the values that form the symbolic

backdrop against which scholarship is evaluated. Numeric measures such as publication output and citation statistics may be benchmarks for research governance (Nederhof, 2006), but they do not fully capture the broad range of peer judgments that permeate academic culture (Becher \& Trowler, 2001; Knorr Cetina, 1999). These judgments assess a wide variety of virtues mobilized in academia, which appear to be more fluid and ambiguous than the virtues reflected in merely statistical measures, and thus are difficult to conceptualize. Not surprisingly, most investigations cover a broad spectrum of qualities and virtues, ranging from professional characteristics such as “originality” (Guetzkow, Lamont \& Mallard, 2004) and "excellence" (Lamont, 2009) to personal traits such as "intellect" (Tsay et al., 2003), “persistence" (Hermanowicz, 2006), and "charisma" (Gustin, 1973).

While contributing a great deal to the scholarly understanding of peer review and (e)valuation, as well as their underlying virtues and values, these two strands of research have focused primarily on academic judgments that target very specific aspects of academic life. For example, the focal review practices are often geared toward the orientation of a journal, the quality of a research proposal, or the compatibility between an applicant and a department. Academics' judgments and classifications of one another's research biographies as a whole have not yet received much attention. This void is surprising considering the centrality of biographical trajectories to the constitution of subjective identities.

Contemporary biography research highlights the relevance of narrative and positioning practices for the formation of identities. It draws especially on pragmatic, performance-based claims to identity and subjectivity (Bamberg, 2010; Georgakopoulou, 2006). Biographical trajectories bring academic subjects into being by representing where researchers come from, what their fields of expertise are, who their friends and foes are, and what they have achieved. 
These are proofs of the final publication that is available at Elsevier via Poetics, doi:10.1016/j.poetic.2016.02.005,

http://www.sciencedirect.com/science/article/pii/S0304422X16000164

A third strand of research has adopted this broader focus by addressing the question of

how academics judge and categorize one another at a more general level: studies on academic positioning have identified a variety of ways in which scholars occupy positions in academia and ascribe certain positions to others. The literature examines positions as identities, roles, and subjectivities that emerge from the dynamic attribution of, for example, expertise, institutional status, or reputation. ${ }^{1}$ This research highlights the structural constraints and opportunities of positioning by examining how intellectual, cultural, institutional, and social conditions influence the legitimacy of a position (Baert, 2011; Lamont, 1987; Maeße, 2015; Morgan \& Baert, 2015). Academic positioning has also been studied in terms of how intellectual self-concepts and self-narratives affect academic self-positioning (Gross, 2002; Lamont, Kaufman \& Moody, 2000). In addition, this strand of research has stressed the importance of conflict and power, analyzing, for example, the way in which academics engage in symbolic struggles, pre-reflexively pursuing certain positioning strategies based on their endowment with different types of capital (Bourdieu, 1988). Research has also described positioning as a practical problem; studies in this area focus on academics' ongoing engagement in both a multitude of positioning dilemmas in power-knowledge complexes (Angermuller, 2013, 2014; see also Baert, 2012) and in boundary work that establishes and reinforces demarcations between fields of knowledge (Abbott, 1995; Gieryn, 1999; see also Lamont \& Molnár, 2002). This strand of the literature facilitates an understanding of the dynamics and practices involved in academics' ascription of certain roles to themselves and others. While valuable, few of these analyses have extrapolated their findings beyond empirical studies of particular and situational positioning practices. Thus, certain key questions remain unanswered; for example: How do comprehensive, holistic accounts of academic subjects emerge from situational ascriptions of academic roles and titles, and what underlying customary rules guide this biographical positioning? 
These are proofs of the final publication that is available at Elsevier via Poetics, doi:10.1016/j.poetic.2016.02.005,

http://www.sciencedirect.com/science/article/pii/S0304422X16000164

Gaining insight into the holistic construction of academic lives is not least a matter of obtaining appropriate empirical data. Although the construction and ascription of overarching identities are fundamental in academia, the practices and dynamics involved in these processes are rarely disclosed or easily accessible. Research in the cultural history of science has utilized the literary genre of biographies as an empirical source (Govoni \& Franceschi, 2014; Terrall, 2006) to study not only the social, political, and cultural contexts of scholars' lives (Abir-Am, 1991), but also how reputations are shaped and how the genre reflects academic norms (Shortland \& Yeo, 1996; Söderqvist, 2011). Sociological accounts have focused on biographical illusion - the presentation of life courses as coherent and intentional ensembles, conferring a logic to a merely sequential order (Bourdieu, 1998; Wacquant, 2000).

Academic obituaries constitute another genre that constructs and (e)valuates academic lives. This genre is more suitable than biographies for studying the consecration of research biographies and the underlying customary rules guiding this consecration for three reasons: the texts are published in academic journals and publications of professional associations, they are written by peers rather than professional biography authors or historians, and they address a purely academic audience, rather than a broader public. Prior research using newspaper obituaries falls into two categories: the most common and extensively used approach, developed by Bridget Fowler, addresses the question of which individuals societies choose to remember in obituaries. Fowler has employed a Bourdieusian framework to analyze newspaper obituaries as contributions to collective memory (Fowler, 2005, 2007; Fowler \& Bielsa, 2007). Similar works have explored gender differences in death notices (Eid, 2002; Rodler, Kirchler \& Hölzl, 2001) and examined the role obituaries play in nationbuilding by publicly distributing grievability (Butler, 2004). 
These are proofs of the final publication that is available at Elsevier via Poetics, doi:10.1016/j.poetic.2016.02.005,

http://www.sciencedirect.com/science/article/pii/S0304422X16000164

While this strand of analysis asks who appears in obituaries, a second approach to

research on newspaper obituaries entails a stronger constructivist emphasis, focusing on how canonization occurs. These studies concentrate on the symbolization of identity projects and claims (Bonsu, 2007; Long, 1987) or certain expectations and prejudices (Bytheway \& Johnson, 1996) in obituaries. Both strands draw on newspaper obituaries to address questions on memory practices and ascriptions. However, the consecration of research biographies can best be examined in obituaries that have been produced from within and for the academic field. While newspaper obituaries embody broader societal consecrations, academic obituaries allow insights in the specific practices and customary rules of academic canonization. Among the few studies of academic obituaries is Tight's (2008) analysis of whether and how certain aspects of academia are portrayed in the genre. Tight concludes that the strong influence of both the American higher education system and Oxbridge, as well as the dominance of men, are reflected in obituaries. Other research on academic obituaries has focused on characteristics such as "intellectual leadership", "societal engagement", and "internationality" that the genre attributes to deceased scholars (Hamann, 2015; Hamann \& Zimmer, 2016; Macfarlane \& Chan, 2014).

The current article contributes to the small but growing body of literature on obituaries, specifically academic obituaries. The analysis applies the consecration of biographies that occurs in obituaries to academia, revealing positioning and narratives as (e)valuative practices that canonize entire academic life courses. The results make a more general contribution to the literature on academic (e)valuation by examining holistic judgments of research biographies. 


\section{Data and methods}

\section{http://www.sciencedirect.com/sciencelarticle/pii/S0304422X16000164}

Conventionally, the data used to examine academic (e)valuation and research biographies are generated via interviews or participant observation. While these modes of data collection undoubtedly have certain advantages, the resulting "contrived" or "artificial" data will, to a certain extent, be reactive to social desirability or the research question of the respective research project. In contrast, obituaries are "naturally" occurring data that offer insight into the logic and process of (e)valuation - insight that is difficult to obtain due to the sensitivity of the topic - without being reactive to researchers or their questions and assumptions. ${ }^{2}$ Nonetheless, the obituary genre entails its own idiosyncrasies. They can be emphasized in contrast to the distinctive characteristics of related "evaluative" genres such as biographies, recommendation letters, and journal peer reviews:

- Who is the author? Authors of obituaries usually have a special relationship to the deceased, who might have been a friend, a pupil or a close colleague. This relationship is reflected in being deemed an appropriate spokesperson to judge the decedent in the name of the group (Bourdieu, 1988:213). In this way, obituaries are similar to recommendation letters, which are written under the assumption that the author knows the recommended person well (Tsay et al., 2003). Biographies might occasionally be written by family members, but are usually authored by professional writers rather than peers (Söderqvist, 2011). Lastly, the peculiar relationship between authors of obituaries and the deceased marks a stark difference from journal peer reviews, which attempt to avoid any visible relationship between the reviewer and the evaluated object (Armstrong, 1997).

- Who/what is the object? Obituaries encompass entire biographical trajectories. In contrast, recommendation letters are less comprehensive because they focus on specific qualifications relevant to the recipient's purposes, while journal peer reviews 
These are proofs of the final publication that is available at Elsevier via Poetics, doi:10.1016/j.poetic.2016.02.005,

http://www.sciencedirect.com/science/article/pii/S0304422X16000164

are geared only toward a specific manuscript. Both biographies and obituaries

conceptualize their objects similarly by focusing on life courses. While biographies in general have expanded to include portrayals of working-class lives and women (Vincent, 1981), biographies of academics still focus solely on the highest status scholars. Academic obituaries do not entail quite as high a degree of selectivity relative to academic biographies, they are less dependent on scholarly status or reputation (see Fowler \& Bielsa, 2007 for a discussion of newspaper obituaries, which exhibit a high degree of social closure via a narrow selection of their objects). ${ }^{3}$ However, being consecrated via an obituary is also contingent upon, for example, social networks (Bourdieu, 1988:215-216; Tight, 2008:134).

- Who is the audience? Obituaries address a somewhat narrow audience: a scientific school, community, or discipline that the decedent is believed to have been part of. The intended audience influences the publication in which an obituary is published. In contrast, biographies address a broader audience and assume a more general interest (Shortland \& Yeo, 1996), while recommendation letters and journal peer reviews address a very limited number of readers. In contrast to biographies, peer reviews, and recommendation letters, obituaries also regularly address their (imagined) audience (e.g., "those of us who knew him" [Kopal, 1972:265]), and thus involve the audience more explicitly in the (e)valuative discourse.

- What is the purpose? The main purpose of obituaries is to consecrate a lifetime of academic achievements. Obituaries, particularly academic obituaries (Macfarlane \& Chan, 2014; Tight, 2008), constitute a laudatory evaluative genre that tends to gloss over negative issues and leaves little room for explicit critique (but see Fowler, 2007:63). Biographies, in contrast, document the life courses of academics in a documentary rather than tributary style. Hence, the genre allows space for 
These are proofs of the final publication that is available at Elsevier via Poetics, doi:10.1016/j.poetic.2016.02.005,

http://www.sciencedirect.com/science/article/pii/S0304422X16000164 waywardness, dilemmas, and even tragedies. Despite these differences, both obituaries and biographies craft and arrange lives as continuous and directed trajectories (Bourdieu, 1998; Wacquant, 2000). In contrast, recommendation letters represent a personal endorsement of a candidate's ability to fulfill a specific post based on specific qualifications, and journal peer reviews critically assess a specific manuscript for publication in a particular journal.

- What are the effects? For objects of evaluative genres, the effect is, per definition, one of different degrees of acknowledgement, ranging from the sometimes outright rejection of journal articles to constructive critique, from the endorsement of candidates in recommendation letters to the documentation of academic lives in biographies and canonization in obituaries. Authors experience notable effects as well: writing an obituary and making the final judgment of an acknowledged researcher promises reputational gains (Bourdieu, 1988). Outside of historiography, writers of biographies cannot expect to earn an academic reputation for their detailed knowledge of high status scholars. Recommendation letters do not contribute to the reputations of their authors because they reach a limited audience. Similarly, the anonymity of the peer review process means that reviewers usually remain unknown, and thus cannot expect reputational gains (Armstrong, 1997). ${ }^{4}$

While obituaries are less reactive to the focal research questions than "artificial" data would be, their contrastive characterization shows that they are nonetheless produced in certain social contexts, geared toward specific purposes, and located in particular configurations that must be reflected in the analysis. For example, while obituaries are an excellent source for revealing the customary rules of consecration due to their laudatory bias, other tonalities of (e)valuation - disagreement, critique, intimidation, attacks - are expressed only very subtly and cautiously, if at all. In addition, due to their focus on whole life courses, obituaries offer 
These are proofs of the final publication that is available at Elsevier via

Poetics, doi:10.1016/j.poetic.2016.02.005,

http://www.sciencedirect.com/science/article/pii/S0304422X16000164

excellent insight into the consecration of research biographies, while other modes of

academic (e)valuation - including modes geared toward more detailed academic distinctions, or explicitly comparative modes - are rarely visible due to the peculiar character of the genre.

The current study is based on a sample of 216 obituaries; this sample was drawn from a population of 841 obituaries collected from academic publications published in the United States, the UK, and Germany. Stratified disproportional sampling was employed, a strategy that divides the population into relevant subgroups or strata, and applies different sampling ratios to these subgroups in order to ensure the same level of representation for each subgroup in the sample. This strategy facilitates variance and creates theoretically relevant comparative dimensions (Patton, 2002). In the focal sample, the subgroups country, discipline, and phase each contain 72 cases. The subgroups in the country stratum are the United States, the UK, and Germany; the subgroups in the discipline stratum are history, sociology, and physics; and the subgroups in the time stratum are the 1960s, the 1980s, and the 2000s (see Table 1$)^{5}$

Table 1 Distribution of obituaries by sample strata

\begin{tabular}{|c|c|c|c|c|c|}
\hline & & $1960-1970$ & $1980-1990$ & $2000-2010$ & Total \\
\hline \multirow{3}{*}{$\dot{\ddot{\nu}}$} & Physics & 8 & 8 & 8 & \multirow{3}{*}{72} \\
\hline & History & 8 & 8 & 8 & \\
\hline & Sociology & 8 & 8 & 8 & \\
\hline \multirow{3}{*}{ 光 } & Physics & 8 & 8 & 8 & \multirow{3}{*}{72} \\
\hline & History & 8 & 8 & 8 & \\
\hline & Sociology & 8 & 8 & 8 & \\
\hline \multirow{3}{*}{$\begin{array}{l}\text { 言 } \\
\text { : } \\
0\end{array}$} & Physics & 8 & 8 & 8 & \multirow{3}{*}{72} \\
\hline & History & 8 & 8 & 8 & \\
\hline & Sociology & 8 & 8 & 8 & \\
\hline \multicolumn{2}{|c|}{ Total } & 72 & 72 & 72 & 216 \\
\hline
\end{tabular}


These are proofs of the final publication that is available at Elsevier via

Poetics, doi:10.1016/j.poetic.2016.02.005,

http://www.sciencedirect.com/sciencelarticle/pii/S0304422X16000164

The choice of subgroups followed the principle of theoretical sampling (Strauss \& Corbin, 1990). Cases are spread across three countries that represent major national higher education systems. To varying degrees, all three countries are part of the global academic center (BenDavid, 1977). Over time their higher education governance regimes have occupied different positions on a spectrum of national statist and neoliberal orientations. The three decades covered by the data capture the main stages of major trends in higher education, especially neoliberalization (Popp Berman, 2012) and internationalization (Altbach, 2013). The three disciplines cover a spectrum from humanities to the social sciences to the natural sciences. These disciplines account for three academic cultures (Snow, 1963), and allow the examination of the production of social knowledge not only for a well-researched discipline from the natural sciences, but also for rather unexplored disciplines in the social sciences and humanities (Camic, Gross \& Lamont, 2011; Dayé, 2014). While future research based on this sample will be able to account for differences between countries, disciplines, and time frames, the current research concentrates on overarching practices and general patterns. The results presented here can therefore be generalized to academic obituaries from major national higher education systems published since the 1960s.

Two additional criteria were used to select cases from the overall population. First, only obituaries that could be unequivocally attributed to a specific discipline and country were selected (as determined by the profile of a journal, and the author and the deceased). Second, the selection of obituaries ensures both sufficient variability between journals of a discipline and at the same time consistency over time. Following these sampling guidelines, obituaries were drawn from 59 specific publications, including academic journals (e.g., Past \& Present for UK history, Social Forces for U.S. sociology) and publications from professional associations (e.g., Footnotes for U.S. sociology, Physikalische Blätter/Physik Journal for German physics). ${ }^{6}$ 
These are proofs of the final publication that is available at Elsevier via Poetics, doi:10.1016/j.poetic.2016.02.005,

Using a grounded theory approach and ATLAS.ti coding software, a first phase of open

coding was conducted with the goal of identifying prevalent themes by categorizing data according to content (Strauss \& Corbin, 1990). Several recurring codes referring to the (e)valuation of research biographies emerged in this initial round of analysis. A second round of axial coding (a grounded theory procedure used to relate, interconnect, and refine categories) was conducted until the analysis reached the point of theoretical saturation and no new subthemes or relationships could be found. This procedure led to the categories presented in the current article (Strauss \& Corbin, 1990:143). A third and last round of coding focused on this select subset of codes and patterns to develop a coherent explanatory and interpretative concept.

\section{Consecrating research biographies via positioning and narratives}

The analysis examines the consecration of research biographies by focusing on practices of (e)valuation and the customary rules that guide these practices. To achieve this, the study does not focus on the specific depiction of individual careers, but rather analyzes a range of depictions of academic careers to reveal typical and characteristic patterns. In order to achieve a first general overview, the following sections will examine the most prevalent features of the consecration of research biographies (based on overall frequency, explicitness, and conspicuousness). However, this focus on the most salient positioning and narrative practices should not suggest the absence of national, disciplinary, or time-based differences in how obituaries consecrate research biographies.

The two most common aspects of the consecration of academic biographies in obituaries are (e)valuative positioning practices and (e)valuative narrative practices. First, (e)valuative positioning practices (4.1) place researchers in relation to others and locate them in various settings. Second, obituaries draw on (e)valuative narrative practices (4.2) to 
These are proofs of the final publication that is available at Elsevier via Poetics, doi:10.1016/j.poetic.2016.02.005,

http://www.sciencedirect.com/science/article/pii/S0304422X16000164

legitimize the diverse stations and achievements of a life course by consolidating them into a unified and linear biographical artifact. Both positioning and narrative practices depict academic lifetime achievements according to customary rules of (e)valuation.

\subsection{Attributing positions}

Examining how obituaries evaluate academic biographies by positioning them in research communities, in institutional and symbolic contexts, and in relation to other scholars, the analysis reveals two main positioning practices: ascriptions to positions in spheres of academic knowledge (e.g., "expert on ...", “pupil of...”) and ascriptions to specific posts in the sphere of institutional academia (e.g., "visiting professor at...”, “director of...”). Occasionally, these two modes of positioning are combined with other, less frequent modes of positioning. At times, for example, researchers are positioned in political spheres. This is the case when obituaries highlight a decedent's engagement in political projects such as nuclear disarmament (French, 2008:116), or refer to the deceased as a national conservative (Gollwitzer, 1967:305) or a patriot (Peterson, 1988:248). Obituaries can also position decedents in a private sphere, depicting them, for example, as a "loving, devoted, dutiful husband and father" (Bebb, 1983:498). It is not uncommon for male researchers to benefit from their wives' support (Kopal, 1972:265; Strasser, 1986:142), although such references are less frequent in more recent obituaries. Both the political and the private sphere are rather marginal in the sample obituaries; they are mentioned selectively and in single passages and do not systematically structure the positioning as a whole. In contrast, the two main modes of positioning, which are most prevalent throughout the countries, disciplines, and time periods in the sample, do systematically guide the positioning. 
These are proofs of the final publication that is available at Elsevier via Poetics, doi:10.1016/j.poetic.2016.02.005,

http://www.sciencedirect.com/science/article/pii/S0304422X16000164

\subsubsection{Positioning in spheres of academic knowledge}

In the first mode of positioning, obituaries locate the decedents in spheres of academic knowledge by defining their academic relevance, their fields of expertise, the communities to which they belonged, and usually their home discipline. This process not only locates researchers in social spheres, but also determines the scholarly value of their contributions and merits in these contexts.

At the beginning of the text, decedents are usually positioned by assessing their overall academic standing in a certain discipline. In a broader sense, these introductory claims set the stage for the obituary and define the research community being addressed. Via these references to overall academic standing, obituaries address communities of varying sizes. For example, introducing the decedent as "[o]ne of the giants of sociology" (Coleman \& Lindenberg, 1989:283) or "one of the most respected historians of his generation" (Clarke, 2010:137) references a very broad audience. In contrast, describing the decedent as "one of the most notable advocates of Medieval economic history" (Aubin, 1967:572) or an “exemplary historian of ideas" (Edelstein, 1963:451) creates a position in a more limited, specific research field. These cases illustrate how introductory positioning evokes not only whom the community is mourning, but also which community the author of the obituary is claiming to speak for, and who will find the subsequent canonization relevant.

A second characteristic element of academic knowledge positioning is the creation of relational symbolic ties between the deceased and iconic researchers in the field. The author may note, for example, that "prominent sociologists such as Parsons explicitly identified with [the researcher's] position" (Strasser, 1986:142-143); or that the researcher's “assessor [advisor] was, very appropriately, Eric Hobsbawn [sic]" (Loftus, 2001:302) - who, in his own obituary is, in turn, positioned in relation to his "great friend Edward Thompson" (Foster, 2013:8-9). These remarks consecrate decedents by positioning them in relation to 
These are proofs of the final publication that is available at Elsevier via

Poetics, doi:10.1016/j.poetic.2016.02.005,

http://www.sciencedirect.com/science/article/pii/S0304422X16000164

other, often canonical, academic subjects. The same effect can be achieved via shorter

remarks when an obituary mentions departmental colleagues (French, 2008:115) or

collaborators (Killian, 1965:30), or compares the deceased to the founding fathers of a field

such as Planck and Einstein (Brüche, 1960:257), Weber (Bonnell, 1991:v), or Mommsen

(Morris, 1970:147). Relational positioning typically evokes a canonical group of commonly recognized figures in the field who serve as reference points for the academic position of the deceased. In these examples, positioning does not signal overall relevance directly, as has been seen for introductory claims, but it symbolizes significance indirectly, via references to distinguished scholars and symbolic ancestral lines.

In addition to introductory and relational positioning, a third typical element of academic knowledge positioning involves the intervention of the author (see Foucault, 1977 for the notion of the author). Authors of obituaries regularly come to the fore to address readers directly, depicting the deceased by referencing their own personal experiences, value judgments, or their personal relationship with the deceased. For example, an author might evoke his "generation," for which the deceased "personified contemporary history" (Medlicott, 1969:201); provide personal value judgments (e.g., "one must recognize, I believe, that he has contributed more than any other person" [Blumer, 1967:103]), or describe personal interactions, recollecting that "we exchanged many letters" (Gombrich, 1981:337). This mode of positioning is a variant of the creation of relational symbolic ties described above, however in these cases it is the author who serves as the figure the deceased is placed in relation to. Crucially, this type of statement also demarcates the position of the author.

While occurring regularly, these personal interjections of the author remain limited to single passages. In all academic obituaries, the author normally speaks on behalf of a community. For example, the author might state that "we grieve...our guide and counselor" (Edelstein 1963:451), extend an invitation to "let us...salute one of our kind" (Howkins, 
These are proofs of the final publication that is available at Elsevier via Poetics, doi:10.1016/j.poetic.2016.02.005,

http://www.sciencedirect.com/science/article/pii/S0304422X16000164

1988:217), or bemoan that "we [have lost] a colleague that achieved a lot for our profession"

(Münch, 1987:625). These assertions of academic relevance are posed from a collective rather than an individual point of view. Not only do these collective references symbolize which school, scientific community, or epistemic collective the author is speaking for, and which of these the deceased belonged to. The voice of a community also appears as a different type of judge than the personal voice of the author. While both voices can be equally powerful and valid, the use of the collective voice of the community makes a claim to intersubjective validity, while the use of the author's personal voice gains its validity precisely from its subjective nature.

\subsubsection{Positioning in the sphere of institutional posts}

Institutional posts are a second type of position that obituaries frequently ascribe to scholars, marking decedents as, for example, visiting fellows, deans, or journal editors. At the beginning of an obituary, decedents might be evoked as "Professor of Sociology at Virginia Polytech Institute and State University" (Hargens \& Gieryn 1988:572); "emerita for medieval and modern history [...] at the University of Bonn" (Fouquet, 2000:1); and "Chairman of the Physics Department, Rice University“ (Richards, 1962:1). In some instances, the first section of the text even traces an institutional trajectory, stating, for example, that the researcher "taught in the Philosophy Departments at Fordham University and U.C.L.A., and then [...] became [a] lecturer in History of Science and Philosophy at the Warburg Institute." (Henry, 1986:337) Even a lack of institutional positions, although rare, must be marked; in one case, for example, an obituary describes a researcher as a "wealthy free-lance historian" (Medlicott, 1969:201). The fact that both the academic and the institutional spheres are addressed in the very first lines of most obituaries highlights their relevance for the positioning of academic subjects and the subsequent consecration of research biographies. 
These are proofs of the final publication that is available at Elsevier via Poetics, doi:10.1016/j.poetic.2016.02.005,

http://www.sciencedirect.com/science/article/pii/S0304422X16000164

Although almost always taking place very early in the text, the ascription of

institutional posts is not limited to introductory passages; rather, researchers are repeatedly located within the institutional sphere throughout the text. In the sample, researchers are brought into being in the institutional spaces of academia via references to their occupying university posts as professors (French, 2008:115), vice chancellors (Schwarz, 1999:594), or guest professors (Strasser, 1986:143). These examples reflect the broad variety of institutional posts that legitimate research trajectories encompass. Similar to positions in academic spheres, institutional positions are not merely mentioned, but are qualified by ascribing institutional relevance, honoring achievements, and highlighting vital contributions for institutional sites including professional associations (French, 2008:116), journals (Foster, 2013:3), and advisory committees (Hargens \& Gieryn 1988:573). This practice emphasizes, as explicitly noted in one case, "the vital significance of basic organizational work on behalf of a scientific discipline" (Blumer, 1967:103).

\subsubsection{The interplay of academic and institutional positioning}

The two modes of positioning (in spheres of academic knowledge and of institutional posts) reveal the spaces that are most important for evoking research subjects and defining and locating who it "is" that the obituary depicts. Two decisive biographical stages, the attainment of the $\mathrm{PhD}$ and retirement, can shed light on the interplay of these two modes of positioning.

In the focal obituaries, the attainment of the $\mathrm{PhD}$ is conveyed as the starting point of an academic career. This is the biographical episode in which academic subjects are brought into existence by being defined and located for the very first time. In this process, obituaries outline the symbolic and institutional parameters of the $\mathrm{PhD}$, namely its specific topic and the granting university or department. For example, researchers are depicted as earning a "doctorate... at University College, London" while participating in "researches on organic 
These are proofs of the final publication that is available at Elsevier via

Poetics, doi:10.1016/j.poetic.2016.02.005,

http://www.sciencedirect.com/science/article/pii/S0304422X16000164

reaction mechanisms" (Stein, 1973:137); obtaining a "PhD...from Harvard's Department of

Social Relations" (Hargens \& Gieryn 1988:572); and earning a doctoral degree “in

Bonn...with a study on the self-administration of the cities in the Saarland" (Fouquet,

2000:1). The attainment of a $\mathrm{PhD}$ is therefore presented as bringing researchers into being by simultaneously locating them within both spheres: academic knowledge and institutional posts. Chronologically, this is the first time the two spheres become intertwined.

Retirement, which occurs at the other end of an academic life, also sheds light on the relationship between knowledge and institutional spheres. Obituaries characterize retirement as a phase in which no major institutional post is occupied. Posts like a professorship "in Birkbeck College", for example, are only occupied "until...retirement" (Foster, 2013:7). This is why descriptions of retirement years in the focal obituaries depict an interesting relationship between the academic knowledge and institutional spheres: they portray the scholars as having given up their most important institutional posts, but remaining active in research. In other words, although retirement signals an exit from the institutional sphere, it does not entail an exit from the sphere of academic knowledge. In fact, retirement is frequently described as a stage in which scholarly work persisted; for example, obituaries note that researchers were "still growing in professional stature" (Killian, 1965:30); were "gathering the harvest" and publishing "book after important book and study after profound study" (Gombrich, 1981:346); and "enjoy[ed] an exceedingly productive retirement" (Fouquet, 2000:1). These passages show that the retirement stage is quite relevant to the biographical trajectories consecrated in obituaries. Although they no longer have a major institutional affiliation, researchers are still acknowledged as academic subjects. In fact, because their positions can no longer be defined in institutional terms, the academic sphere becomes even more prominent; one text, for example, highlights a scholar's almost restless “scholarly activity until the very end.” (Lynch, 2011:927) 
These are proofs of the final publication that is available at Elsevier via

Poetics, doi:10.1016/j.poetic.2016.02.005,

http://www.sciencedirect.com/science/article/pii/S0304422X16000164

In sum, ascribing certain positions in knowledge and institutional spheres to decedents

is a central practice that consecrates research biographies. Ascribed to institutional posts and located in relation to disciplines, communities, and other scholars, researchers are not only categorized, but also created as such throughout the text. Adhering to and reinforcing the customary rules of (e)valuation, this classification also includes scholars' academic and institutional relevance, and which community is supposed to acknowledge their respective achievements. Occurring in every obituary in the sample, the two modes of positioning illustrate characteristic ways of ascribing scholarly merits and affiliations that are crucial aspects of legitimate research biographies. With respect to their significance for biographical consecration, positioning in spheres of academic knowledge is more central than positioning in institutional spheres, as it is slightly more frequent and salient in the sample. However, both positioning practices do not compete with each other in the narrow sense, nor are they mutually exclusive.

\subsection{Applying biographical narratives}

While the ascription of positions in obituaries reveals a typical and vital practice of categorizing research subjects, the way in which these various positions are integrated into a coherent biographical unit remains unexamined. The (e)valuative practices that create this overarching coherence for academic lives are biographical narratives. An academic obituary might draw on, for example, a narrative of luck and coincidence. In the sample obituaries, for instance, authors portrayed academic lives as determined by "luck", a "fateful decision" (Peterson, 1988:239-240), or a "peculiar providence” (Kellenbenz, 1969:283). However, while it may actually be important for researchers to be at the right place at the right time, narratives that focus on luck or coincidence as part of a biography are quite uncommon. This is especially true for more recent obituaries of scholars whose careers were not disrupted by war and/or emigration, and who could thus rely on more stable and formalized career paths. 
These are proofs of the final publication that is available at Elsevier via

Poetics, doi:10.1016/j.poetic.2016.02.005,

http://www.sciencedirect.com/science/article/pii/S0304422X16000164

Overall, the sample obituaries employ two primary types of biographical narratives, which are prevalent throughout the period of investigation: narratives of natural talent and narratives of merit. ${ }^{7}$

\subsubsection{Narratives of natural talent}

Narratives of natural talent are a characteristic presentation of academic life courses. They draw on a variety of approaches to depict research biographies as inevitable success stories.

One commonly used approach is the notion of biographical predetermination, which portrays the stations and achievements of a research career with a sense of necessity and inevitability. In these cases, obituaries assert that academic aptitude announced itself very early in life. For example, the focal obituaries make claims such as that the decedent's "attitude determined his choice of study and his method of work from his earliest years" (Morris, 1970:147); and that "a genuine grasp of academic institutions and atmosphere were obvious already as a student" (Gollwitzer, 1967:297). Narratives of natural talent often convey a feeling of fate;

proclaiming, for example, that a researcher "announced at the age of eleven that he was going to be a historian" (Loftus 2001:299), or that the "exceptional talents" of a physicist were evident before he was even five years old, when "his father brought home a crystal radio, which inspired the young [researcher] with a love of more general scientific tinkering" (French, 2008:111). Predetermination can also be evoked by describing the deceased as following a calling, for example a "vocation and calling as a researcher" (Fouquet, 2000:2) or a "historical calling" (Blackbourn, 1990:3). By employing notions of predetermination, narratives portray a life in academia as a destiny that was just waiting to be fulfilled.

In addition to notions of predetermination, narratives of natural talent also attribute successful careers to certain character traits, thereby evoking legitimate academic personalities. Obituaries regularly highlight traits such as curiosity, creativity, and unconventionality as factors responsible for academic honors. Academics in the sample, for 
These are proofs of the final publication that is available at Elsevier via Poetics, doi:10.1016/j.poetic.2016.02.005,

http://www.sciencedirect.com/science/article/pii/S0304422X16000164

example, are characterized as a scholar who "was as much well-behaved as he was irreverent and curious" (Schwarz, 1999:595-596); and as a "prodigiously talented person intellectually brilliant, mesmerizingly eloquent" (French, 2008:110). Other characteristic attributes prevalent in narratives of talent include a "highly creative intellect" (French, 2008:116), “imagination" (Blackbourn, 1990:6), a “critical and smart spirit” (Fouquet, 2000:2), and an "[i]ndifference to convention" (Morris, 1970:149). Character traits such as creativity and critical unconventionality are portrayed as seemingly natural dispositions that characterize honorable academic subjects.

In addition to notions of biographical predetermination and ascriptions of certain character traits, a depiction of the succession of research topics throughout a career is the third element in narratives of natural talent. Obituaries often portray academic biographies as a successful unfolding of natural talent by presenting a coherent and logical succession of research fields across a lifetime, and thus outlining a homogenous research profile that lends consistency to a career. This seemingly natural course of research topics is usually assumed to begin with the granting of the first university degree or with the dissertation. In the hindsight of obituaries, these periods are depicted as a formative stage in which the deceased “took up what became a life-long interest" (Lynch, 2011:929); "received the impulse for a lifelong occupation" (Gollwitzer, 1967:297) with a subject; or "discovered the leading question of [his] scholarly oeuvre" (Schwarz, 1999:595). The customary rules guiding the consecration of research biographies do not allow for interruptions or breaks in research profiles. Depictions of legitimate biographies avoid any references to a sense of strategic choices, phases of disorientation and frustration, and problems researchers encountered in establishing themselves within a certain sub-field.

Characteristically, narratives of talent in academic obituaries present research biographies as a smoothly flowing success story. Natural talent is ascribed to decedents via 
These are proofs of the final publication that is available at Elsevier via

Poetics, doi:10.1016/j.poetic.2016.02.005,

http://www.sciencedirect.com/science/article/pii/S0304422X16000164

three elements: biographical predetermination and inevitability, character traits such as

curiosity and unconventionality, and highly consistent research profiles. Thus, according to these narratives, for those who are endowed with talent, an honorable academic biography develops naturally and automatically.

\subsubsection{Narratives of merit}

Narratives of merit are the second primary depiction of academic lives used in focal obituaries. In these cases, biographies are narrated not on the basis of natural talent, but on the basis of the decedent's hard work, dedication, and even obsession. These narratives emerge, first, through biographical representations of devotion. According to such portrayals, the individual being honored has lived for and been devoted to research in a fundamental way. Focal obituaries, for example, assert that a sociologist "devoted himself to sociology" (Outhwaite, 1993:387) and a historian's "life was entirely devoted to economic history" (Aubin, 1967:572), and describe a physicist's "life in which almost sixty years were devoted to the advancement of astronomy" (Kopal, 1972:265). These ascriptions do not depict a life that was predetermined for and naturally dovetailed with academia, but one that was devoted to, and possibly even sacrificed for, the academic cause.

As in narratives of natural talent, stories of merit also refer to certain character traits in order to make a life course plausible. In this case, traits like modesty, discipline, and determination are ascribed to decedents as the traits responsible for success. In the sample obituaries, researchers are characterized by their "energy and determination" (Kopal, 1972:263), their "tireless commitment” (Münch, 1987:626), and their "meticulous [and] scrupulous" (Liddington, 1984:214) research. Scholars are also honored for their "habitually disciplined work" and "self-criticism" (Wehler, 1985:143, 150), and their "lack of pretentiousness" and "zeal to get things done" (Richards, 1962:2). According to these characterizations, research is not something that happens to those that have the natural talent, 
These are proofs of the final publication that is available at Elsevier via

Poetics, doi:10.1016/j.poetic.2016.02.005,

http://www.sciencedirect.com/science/article/pii/S0304422X16000164

but rather a craft to be mastered via effort and commitment. There is, however, a slight caveat

to these ascriptions of determination: researchers are depicted as not merely industrious, but crucially, enjoying their hard work. Thus, ascriptions of determination are combined with attributions of enthusiasm. The focal obituaries conclude, for example, that a researcher's diligence was driven by an "unbounded enthusiasm for physics" (Richards, 1962:2), and a researcher was able to "carry along a considerable number of staff with his verve", highlighting "his special gift to enthuse staff and colleagues" (Münch, 1987:626). The customary rules of consecration require distinguishing mere industriousness and tedious commitment from a truly honorable academic obsession that in the end appears almost as wondrous as a calling.

In addition to notions of biographical devotion and attributions of particular character traits, a third element of narratives of merit is a specific understanding of the succession of research topics throughout a career. In contrast to the rather homogenous and consistent research profiles depicted in narratives of natural talent, the profiles depicted in narratives of merit do include all-too-obvious changes and even breaks. Crucially though, narratives still rationalize vicissitude by attributing it to external factors. First, some obituaries posit institutional circumstances as an explanation, for example, "scientific interests shifted" (Kopal, 1972:261) when obtaining a position at an observatory allowed a researcher to address certain questions. Second, personal circumstances are presented as leading to shifts, for example, when retirement allowed a scholar to return "to some of the themes... which had concerned [him] much earlier in his career" (Outhwaite, 1993:388); or when “experiences... as a social worker" are "consequently introduced into research" (Münch, 1987:626). Lastly, narratives of merit posit political circumstances as the source of changes; for example, the focal obituaries describe instances in which a researcher "was the first to realize the political importance" (Liddington, 1984:214) of a topic, and "the failure of the 
These are proofs of the final publication that is available at Elsevier via

Poetics, doi:10.1016/j.poetic.2016.02.005,

http://www.sciencedirect.com/science/article/pii/S0304422X16000164

German imperium...led to the conclusion to move from an isolated national history to a

comparative European history" (Wehler, 1985:145). In sum, these narratives of the

succession of research subjects allow for various influences and for the presentation of

strategic choices, breaks, and interruptions. In these cases, obituaries portray research profiles

as decidedly embedded in specific institutional, personal, and political contexts to which the deceased might have reacted in a particular way.

Via narratives of merit, obituaries present research biographies as the result of an academic obsession and hard work. Merit is attributed through devotion; character traits such as modesty, discipline, and determination; and research profiles that may be heterogeneous but remain coherent because shifts and breaks are portrayed as the result of external influences. In contrast to narratives of natural talent, which focus on the inevitability of success that accompanies talent, narratives of merit depict a meritocracy in which successful careers are earned, and all-too-obvious breaks in otherwise linear and necessarily successful trajectories are justified and made plausible.

\subsubsection{Ambivalences: the narration of constraints and hurdles}

The two dominant narratives described above (narratives of natural talent and narratives of merit) are rarely unequivocal and unambiguous - they often contain elements of ambivalence. This section examines the ways in which problematic episodes, constraints, and hurdles are presented and intertwined in the overall biographical narratives.

The depiction of crises, unfulfilled potential, and structural constraints is a delicate matter in the genre. Prior research has shown that obituaries tend to present life courses in a generally positive way (Bonsu, 2007:207-209; Butler, 2004:32; but see Fowler, 2007:63). Academic obituaries gloss over negative issues such as constraints or setbacks to a degree that is remarkable even by the standards of the genre in general (Macfarlane \& Chan, 2014; Tight, 2008). The institutional, social, and psychological hurdles that researchers actually 
These are proofs of the final publication that is available at Elsevier via

Poetics, doi:10.1016/j.poetic.2016.02.005,

http://www.sciencedirect.com/science/article/pii/S0304422X16000164

face in their professional lives - from funding restrictions to personal circumstances - are

typically not mentioned at all. This omission is a result of the censorship exerted by

customary rules of (e)valuation, which call for authors to make sense of research biographies

by evoking subjective and personal agency and internal motives rather than external factors.

There are, however, exceptions to this pattern. Academic obituaries, no matter which biographical narrative they employ, occasionally mention ambivalences and constraints to research careers. Intriguingly, when obituaries portray such challenges they typically reinterpret them and thus lend them a notion of legitimacy in hindsight. Cases in which achievements and recognition appear to have been absent initially highlight this practice. The initial deficiency is then often presented as a misunderstanding that was resolved during the lifetime of the decedent (e.g., "[h]ighly appreciated honours came to him late" [Stein, 1973:139]). In other cases, the author acts as the final judge, reminding the audience that a researcher's "contributions are far more extensive than is often recognized" (Lynch, 2011:928), or that the scholar's "work has often been perceived too one-sided and narrow" (Specht, 1969:124). In these ex-post re-evaluations, therefore, the career is still depicted as free of failures or constraints serious enough to impede the canonization of the decedent.

In sum, biographical narratives are central (e)valuative practices that consecrate lives in academia by depicting research biographies in a particular way. These narratives apply interpretative frameworks of natural talent and merit by including the attribution of specific character traits, depicting the succession of research subjects in a certain way, and highlighting notions of predetermination or of hard work. In doing so, these narratives not only legitimize research biographies, but also evoke them as such in the first place. The overall prevalence of these practices suggests that they embody characteristic conventions of the way in which researchers acknowledge one another. 


\section{Discussion and conclusion}

http://www.sciencedirect.com/sciencelarticle/pii/S0304422X16000164

The analysis revealed two main (e)valuative practices that consecrate research biographies in academic obituaries. As a conclusion, this section discusses the relevance of both positioning and narrative practices for the (e)valuation of research biographies, and suggests how the study of these practices advances research on (e)valuation in general.

The study of positioning practices demonstrates how academic identities are acknowledged and categorized via ascribed positions. Who researchers "are" and who they are perceived to "be" is highly dependent on the type of positional attributions outlined above. In the focal obituaries, salient positioning practices focus mainly on spheres of academic knowledge and institutional posts. Although not the only spheres referred to in the sample, these appear to be the two decisive spaces in which researchers come into being as legitimate subjects (see also Angermuller, 2013). Why is this the case? A likely explanation is that these spheres are most prevalent because they structure academic lives when researchers are still very much alive: researchers struggle for recognition in spheres of academic knowledge by drawing on communities, representing schools of thought, advocating claims, and engaging academically with both their peers and canonical authors. At the same time, researchers struggle to obtain institutional posts such as professorships, chairs, fellowships, and seats on editorial boards. The two spheres that structure the categorization of researchers, both during life and after death, show a striking correlation with the types of capital that structure the academic field as described by Bourdieu (1988).

The prevalent biographical narratives of natural talent and merit illustrate the dominant ways of making sense of academic life courses. They highlight the ways in which authors construct coherent biographical artifacts by integrating various stages and achievements into a single meaningful trajectory. In the focal obituaries, salient narratives refer to natural talent or merit. While other narratives are also employed in the sample, these two are the most 
These are proofs of the final publication that is available at Elsevier via Poetics, doi:10.1016/j.poetic.2016.02.005,

http://www.sciencedirect.com/science/article/pii/S0304422X16000164

common ways of evoking, making sense of and legitimizing a coherent research biography

(see also Wacquant, 2000). Why are these two the most common references? One plausible explanation is that they allow for rather flattering depictions of decedents. Flattery is to be expected, because obituaries are a laudatory evaluative genre that is not documentary in style (in contrast to, for example, biographies), and is even less critical (as, for example, journal peer reviews). An additional explanation for the frequent references to talent and hard work is their contribution to a (re-)production of a meritocracy myth for careers and trajectories (Lewis, 1998; McNamee \& Miller, 2004).

Strikingly, both (e)valuative practices examined in this study (positioning and narrative practices) emphasize certain factors and disguise other determinants of academic biographies: socio-structural determinants such as gender or class are neglected and biographical breaks and hurdles are disguised despite their considerable importance for both biographical trajectories and academic careers. This selective depiction results in very peculiar biographical artifacts that are nonetheless presented as being natural and self-evident. Careers and life courses appear as logical trajectories because they are constructed in spheres of institutional posts and academic knowledge, and made plausible by either talent or determination. Prior research, however, has shown that academic careers are not shaped solely by either natural talent or hard work (Long \& Fox, 1995; Rossiter, 1993; Zippel, 2011), and that researchers are very effectually positioned in other spheres as well - the private sphere in terms of marital status (Wolf-Wenderl, Twombly \& Rice, 2004), the economic sphere in terms of class (Kennelly, Misra \& Karides, 1999; Laurison \& Friedman, 2015), and the political sphere in terms of their political views (Gross \& Fosse, 2012; Klein, Stern \& Western, 2005). Despite these findings, the (e)valuative positioning and narrative practices that consecrate research biographies neglect these factors and spheres. They do not acknowledge highly influential but less glamorous determinants of academic careers like, for 
These are proofs of the final publication that is available at Elsevier via Poetics, doi:10.1016/j.poetic.2016.02.005,

http://www.sciencedirect.com/science/article/pii/S0304422X16000164

example, gender, as an influential factor for academic success. Even among the $5 \%$ of sample obituaries authored by women and the $7 \%$ about women, few texts explicitly refer to the gender of the deceased at all. If they do, obituaries integrate gender into a meritocratic success story in which women "overcame the disadvantages" of their "gender to become an internationally recognized Professor" (Purvis, 2008:363).

Class is another influential determinant of academic careers that is rarely acknowledged in obituaries. In the few cases that mention the social background of the deceased at all, most do so in a sober, documentary fashion, for example, noting merely that a researcher's “father was a naval officer" (Hargens \& Gieryn 1988:572) or "an economic historian" (Loftus 2001:299). The switch from laudatory style to documentary style in these instances is striking. As with gender, obituaries almost never concede that social origin influenced or structured an academic career. The general absence of discussions of determinants such as gender and class, and the focus on personal ascriptions such as talent or merit mean that, in accordance with the customary rules of evaluating research biographies, academic success is attributed to a subjective and personal agency and to internal motives rather than external determinants and factors.

Academic obituaries in the sample reveal a laudatory, meritocratic bias and turn a blind eye to socio-structural determinants of academic careers. Using the current sample, future research on the consecration of research biographies can build on this insight. Scholars should systematically address the social origin of both decedents and authors, thereby illuminating the social selectivity of the genre. Furthermore, future projects should delve more deeply into the specific merits and virtues ascribed to research biographies by systematically examining differences between countries, disciplines, and time periods (see Hamann \& Zimmer, 2016 for a first attempt). 
These are proofs of the final publication that is available at Elsevier via Poetics, doi:10.1016/j.poetic.2016.02.005,

http://www.sciencedirect.com/sciencelarticle/pii/S0304422X16000164

Because obituaries are a particular (e)valuative genre, this second step of the conclusion discusses the implications of the generated insights for sociological research on (e)valuation in general. In her influential attempt to consolidate various bodies of work into a sociology of valuation and evaluation, Michèle Lamont (2012) identified categorization and legitimization as two of the most salient subprocesses of (e)valuation. Dynamics of legitimization include, for example, ritualization, contestation, and, as demonstrated in the current research, consecrating narratives. Dynamics of categorization include, for example, classification, signaling, standardization, and, as this study illustrates, positioning. The current research makes two contributions to a sociology of (e)valuation.

First, the study exemplifies how both the categorization and the legitimization of evaluated objects - in this case via research biographies begotten by positioning and narrative practices - establish and at the same time rely on a number of hierarchical symbolic relations:

- Author $\rightarrow$ deceased: authors of obituaries depict how a specific life in academia has been lived, and what was particularly venerable about it. With their texts, authors consecrate a meaningful biography by locating a dead scholar in certain spaces and embedding her or him in a network of references and relationships.

- Author $\rightarrow$ community: the author evokes the deceased subject, and suggests to the community how this academic life should be remembered. Former pupils or colleagues might not have the opportunity to transfer their view of their deceased colleague or teacher to public memory and thus have to live with the final judgment made by the author.

- Customary rules $\rightarrow$ author: authors cannot consecrate decedents on their own terms. In order to be acknowledged as such by the community, the (e)valuation of a research biography must follow customary rules of consecration that determine how to speak respectfully of the dead, what to emphasize and what to omit. 
These are proofs of the final publication that is available at Elsevier via Poetics, doi:10.1016/j.poetic.2016.02.005,

http://www.sciencedirect.com/science/article/pii/S0304422X16000164

- Community $\rightarrow$ author: because the author of the (e)valuation is acting as a spokesperson for a community, this collective is the authority that holds the author responsible for her or his judgment. The community oversees whether the author's consecration follows customary rules, or whether the depiction of the deceased is perceived as unjust.

- Obituary $\rightarrow$ academics: obituaries present highly legitimate research biographies in a favorable light. Although they are laudatory rather than documentary in character, these biographical representations still appear as natural and self-evident. The implicit comparison with researchers still very much alive might be perceived as pressure to live up to the shining example.

These hierarchical symbolic relations express everyday forms of control, although these forms of control are not merely exerted, destructive or openly violent. They are accepted by both respective parties, appear natural, and are productive because they construct, categorize, and legitimize research biographies. Thus, the current study reconstructs (e)valuative scenarios that are embedded in networks of symbolic power (for the notion of a productive, symbolic form of power see Bourdieu, 1991; Foucault, 1982).

The second contribution the study makes to a sociology of (e)valuation facilitates a more nuanced view of the techniques and conditions of evaluation. Hence, categorizing dynamics (illustrated in terms of positioning) and legitimizing dynamics (illustrated in terms of biographical narratives) are distinguished for heuristic purposes.

Positioning practices can categorize and classify researchers. As illustrated in this study, these practices place subjects in spheres of academic knowledge, ascribe membership in certain schools and communities, and locate decedents in relation to other scholars, especially iconic figures. The relational aspects of positioning can be understood as equivalent to comparative techniques that are used in other academic (e)valuation, for 
These are proofs of the final publication that is available at Elsevier via Poetics, doi:10.1016/j.poetic.2016.02.005,

http://www.sciencedirect.com/science/article/pii/S0304422X16000164

example in journal peer reviews. Just as many peer reviews rank or rate their objects and thereby explicitly compare them, the positioning practices used in obituaries reveal relational ties between the deceased and other scholars. In both cases, value is ascribed and categorization occurs on the basis of external references.

Positioning practices also show how (e)valuative judgments are stabilized (cf. the notion of "black-boxing" in Latour, 1988). Relational positioning emphasizes the important role of (imagined) third parties as stabilizers of the (e)valuation conducted in the obituary. Invoking common ancestral lines and relational ties to other scholars (re-)establishes what, according to the author, can be considered a shared frame of reference. Similarly, authors use two common voices - personal interjections and collective judgments - to make ascriptions plausible, prevent any impression of arbitrariness, and stabilize the (e)valuation so it can be transported across contexts such as communities, countries, disciplines, or generations. However, the stabilizing effect of academic positioning is not limited to (e)valuative judgments. By mobilizing a wealth of common references, including schools, communities, departments and iconic figures, this positioning also stabilizes the coherence of the group. Each act of consecration, therefore, is aimed at the scientific community as much as at the decedent.

As dynamics of legitimization, biographical narratives make sequences understandable as a series of positions connected by the notion of a "subject" (Foucault, 1982). Once evoked, the academic subject is endowed with personal agency and internal motives (via ascriptions such as "talent" or "diligence") while external determinants (e.g., class, gender, biographical hurdles) are not given much attention or are dismissed altogether. It is this peculiar depiction of a subject that is then consecrated and integrated into a canon. In this process, obituaries act as narrative vehicles that transmit researchers deemed important or noteworthy across generations of scholars. Specific depictions of a deceased researcher's biography are thus 
These are proofs of the final publication that is available at Elsevier via Poetics, doi:10.1016/j.poetic.2016.02.005,

http://www.sciencedirect.com/science/article/pii/S0304422X16000164

transferred into the collective memory (Fowler, 2005, 2007) while negative aspects such as biographical constraints and hurdles are regularly entrusted to collective forgetting. This selective intergenerational memorial function is a particular feature of the dynamics of legitimization. In the case of academic obituaries, the memorial function relies on the existence of colleagues, pupils, or even a school or community that has a stake in the perpetuation of the decedent's reputation.

Biographical narratives highlight further conditions required for legitimizing dynamics. In order for the legitimization to be credible, the author must appear well informed to make the judgment. The author of an obituary must be deemed an expert on the life in question - a status that is often signaled by personal interjections in the text. A second condition for legitimizing dynamics is that the author must act as a spokesperson for a community that, in turn, serves as a supervisory authority overseeing the (e)valuation. If the obituary makes a judgment that appears unjust, the author is responsible and her or his reputation may suffer. The standards for the legitimacy and accountability of an evaluation are thus rigorously overseen by the scientific community addressed - a process facilitated by the fact that obituaries (in contrast to, for example, journal peer reviews or letters of recommendation) are public. Finally, the legitimization dynamic relies on a framework of customary values and virtues that the (e)valuation draws on. In the focal obituaries, these virtues are reflected in specific character traits and in the way research profiles are narrated. As noted above, following the customary rules of consecration entails not only emphasizing specific aspects, but also omitting others. Only when the author is aware of this framework and follows the set of customary rules is the consecration of the research biography acknowledged as such in the community. 


\section{Acknowledgements}

http://www.sciencedirect.com/sciencelarticle/pii/S0304422X16000164

This work was supported by a Feodor Lynen Postdoctoral Fellowship of the Alexander von Humboldt Foundation. I would like to thank Kathrin Zippel, Lena M. Zimmer, Jens Maeße, and Vincent Gengnagel as well as four anonymous reviewers for their constructive comments on previous versions of this text.

\section{Appendix}

\section{Obituaries cited in the text}

Aubin, H., 1967. Hektor Ammann. Vierteljahrschrift für Sozial- und Wirtschaftsgeschichte 4, $572-576$.

Bebb, P.N., 1983. In Memoriam: Harold J. Grimm. The Sixteenth Century Journal 4, 497498.

Blackbourn, D., 1990. Tim Mason. Past \& Present 1, 3-6.

Blumer, H., 1967. Ernest Watson Burgess, 1886-1966. The American Sociologist 2, 103-104.

Bonnell, V., 1991. In Memory of Reinhard Bendix. Berkeley Journal of Sociology 36, i-v.

Brüche, E., 1960. Abschied von Max von Laue. Physikalische Blätter 5, 257-258.

Clarke, P., 2010. Duncan Tanner. Twentieth Century British History 2, 137-140.

Coleman, J.S., Lindenberg, S., 1989. In Memoriam: George Homans. Rationality and Society 2, 283-284.

Edelstein, L., 1963. In Memory of A.O. Lovejoy. Journal of the History of Ideas 4, 451-456.

Foster, R., 2013. Eric Hobsbawm. Past \& Present 1, 3-15.

Fouquet, G., 2000. Edith Ennen (1907-1999). Vierteljahrschrift für Sozial- und Wirtschaftsgeschichte 1, 1-4.

French, A.P., 2008. In Memoriam Philip Morrison. Physics in Perspective 10, 110-122. 
Gollwitzer, H., 1967. Karl Alexander von Müller 1882-1964: Ein Nachruf. Historische

Zeitschrift 2, 295-322.

Gombrich, E.H., 1981. In Memory of George Boas. Journal of the History of Ideas 2, 334354.

Hargens, L.L., Gieryn, T.F., 1988. Nicholas C. Mullins (1939-88). Social Studies of Science $3,572-573$.

Henry, J., 1986. Obituary: Charles Bernard Schmitt: 1933-1986. The British Journal for the History of Science 3, 337.

Howkins, A., 1988. George Ewart Evans, 1909-1987. History Workshop Journal 26, 215217.

Kellenbenz, H., 1969. Götz Freiherr von Pölnitz. Vierteljahrschrift für Sozial- und Wirtschaftsgeschichte 2, 282-288.

Killian, L.M., 1965. Meyer Francis Nimkoff (1904-1965). The American Sociologist 1:30.

Kopal, Z., 1972. In Memoriam Harlow Shapley. Astrophysics and Space Science 18, 259266.

Liddington, J., 1984. Gloden Dallas (1943-1983). History Workshop Journal 1, 213-214.

Loftus, D., 2001. Robert Q. Gray (1945-2001). History Workshop Journal 52, 299-303.

Lynch, M., 2011. Harold Garfinkel (29 October - 21 April 2011): A remembrance and a reminder. Social Studies of Science 6, 927-942.

Medlicott, W.N., 1969. G.P. Gooch. Journal of Contemporary History 4, 201-203.

Morris, J., 1970. A. H. M. Jones. Past \& Present 1, 147-150.

Münch, R., 1987. In memoriam Hans Haferkamp (15.09.1939-14.07.1987). Kölner Zeitschrift für Soziologie und Sozialpsychologie 39, 625-628.

Outhwaite, W., 1993. Tom Bottomore: Born 8.4.20. Died 9.12.92. Sociology 3, 387-399. 
Peterson, M.D., 1988. Dumas Malone: An Appreciation. The William and Mary Quarterly 2, 237-252.

Purvis, J., 2008. Olive Banks (1923-2006): an appreciation. British Journal of Sociology of Education 4, 363-368.

Richards, H.T., 1962. T. W. Bonner (1910-1961). An obituary. Nuclear Physics 32, 1-4.

Schwarz, H.-P., 1999. Nachruf auf Theodor Eschenburg, Vierteljahrshefte für Zeitgeschichte 4, 593-600.

Specht, K.G., 1969. Leopold v. Wiese. Soziale Welt 1, 124-125.

Stein, G., 1973. In Memoriam J.J. Weiss (1905-1972). International Journal of Radiation Physics and Chemistry 5, 137-139.

Strasser, H., 1986. Werner Stark - Gelehrter und Katholik: 1909-1985. Zeitschrift für Soziologie 2, 141-145.

Wehler, H.-U., 1985. Nachruf auf Theodor Schieder: 11. April 1908-8. Oktober 1984. Geschichte und Gesellschaft 1, 143-153.

\section{References}

Abbott, A., 1995. Things of Boundaries. Social Research 62, 857-882.

Abir-Am, P., 1991. Nobelesse Oblige: Lives of Molecular Biologists. Isis 82, 326-343.

Altbach, P.G., 2013. The International Imperative in Higher Education SensePublishers, Rotterdam.

Angermuller, J., 2013. How to become an academic philosopher. Academic discourse as multileveled positioning practice. Sociología histórica 2013, 263-289.

Angermuller, J., 2014. Poststructuralist Discourse Analysis. Subjectivity in Enunciative Pragmatics. Palgrave Macmillan, Houndsmill, Basingstoke. 
Armstrong, J.S., 1997. Peer review for journals: Evidence on quality control, fairness, and innovation. Science and Engineering Ethics 3, 63-84.

Baert, P., 2011. The sudden rise of French existentialism: a case-study in the sociology of intellectual life. Theory and Society 40, 619-644.

Baert, P., 2012. Positioning Theory and Intellectual Interventions. Journal for the Theory of Social Behaviour 42, 304-324.

Bakanic, V., McPhail, C., Simon, R.J., 1987. The Manuscript Review and Decision-Making Process. American Sociological Review 52, 631-642.

Bamberg, M.G.W., 2010. Who am I? Narration and its contribution to self and identity. Theory \& Psychology 21, 1-22.

Becher, T., Trowler, P., 2001. Academic Tribes and Territories: Intellectual Enquiry and the Cultures of Disciplines. Open University Press, Philadelphia.

Ben-David, J., 1977. Centers of Learning: Britain, France, Germany, United States. McGrawHill Book Company, New York.

Bonsu, S.K., 2007. The Presentation of Dead Selves in Everyday Life: Obituaries and Impression Management. Symbolic Interaction 30, 199-219.

Bornmann, L., Daniel, H.-D., 2005. Selection of research fellowship recipients by committee peer review: Analysis of reliability, fairness and predictive validity of Board of Trustees' decisions. Scientometrics 63, 297-320.

Bourdieu, P., 1988. Homo Academicus. Polity Press, Cambridge.

Bourdieu, P., 1991. Language and Symbolic Power. Polity Press, Cambridge.

Bourdieu, P., 1998. Die biographische Illusion, in: Bourdieu, P. (Ed.), Praktische Vernunft. Zur Theorie des Handelns. Suhrkamp, Frankfurt/M., pp. 75-90.

Butler, J., 2004. Precarious Life. The Power of Mourning and Violence. Verso, London, New York. 
Bytheway, B., Johnson, J., 1996. Valuing lives? Obituaries and the life course. Mortality 1, 219-234.

Camic, C., Gross, N., Lamont, M., 2011. Social Knowledge in the Making. University of Chicago Press, Chicago.

Dayé, C., 2014. Visions of a Field: Recent Developments in Studies of Social Sciences and Humanities. Science, Technology, \& Human Values 39, 877-891.

Eid, M., 2002. The World of Obituaries: Gender Across Cultures and Over Time. Wayne State University Press, Detroit, MI.

Foucault, M., 1977. What is an author?, in: Foucault, M. (Ed.), Language, Counter-memory, Practice: Selected Essays and Interviews. Cornell University Press, New York, pp. 113138.

Foucault, M., 1982. The Subject and Power. Critical Inquiry 8, 777-795.

Fowler, B., 2005. Collective Memory and Forgetting: Components for a Study of Obituaries. Theory, Culture \& Society 22, 53-72.

Fowler, B., 2007. The Obituary as a Collective Memory. Routledge, New York.

Fowler, B., Bielsa, E., 2007. The lives we choose to remember: a quantitative analysis of newspaper obituaries. The Sociological Review 55, 203-226.

Georgakopoulou, A., 2006. Thinking big with small stories in narrative and identity analysis. Narrative inquiry 16, 122-130.

Gieryn, T.F., 1999. Cultural Boundaries of Science: Credibility on the Line. University of Chicago Press, Chicago.

Govoni, P., Franceschi, Z.A., 2014. Writing about Lives in Science. (Auto)Biography, Gender, and Genre. Vandenhoeck \& Ruprecht, Göttingen.

Gross, N., 2002. Becoming a Pragmatist Philosopher: Status, Self-Concept, and Intellectual Choice. American Sociological Review 67, 52-76. 
Gross, N., Fosse, E., 2012. Why are professors liberal? Theory and Society 41, 127-168.

Guetzkow, J., Lamont, M., Mallard, G., 2004. What is Originality in the Humanities and the Social Sciences? American Sociological Review 69, 190-212.

Gustin, B.H., 1973. Charisma, Recognition, and the Motivation of Scientists. American Journal of Sociology 78, 1119-1134.

Halsey, A.H., 2004. A History of Sociology in Britain: Science, Literature, and Society. Oxford University Press, Oxford.

Hamann, J., 2015. Posthumous (E)valuation. Research Biographies in US Sociology, as Reflected in Academic Obituaries. Timelines - Newsletter of the ASA Section History of Sociology 2015, 10-13.

Hamann, J., 2016. The visible hand of research performance assessment. Higher Education DOI :10.1007/s10734-015-9974-7.

Hamann, J., Zimmer, L.M., 2016. The Internationality Imperative in Academia. The Ascend of Internationality as an Academic Virtue, Manuscript.

Hermanowicz, J.C., 2006. What Does It Take to Be Successful? Science, Technology, \& Human Values 31, 135-152.

Hirschauer, S., 2010. Editorial Judgements: A Praxeology of 'Voting' in Peer Review. Social Studies of Science 40, 71-103.

Jerolmack, C., Khan, S., 2014. Talk Is Cheap: Ethnography and the Attitudinal Fallacy. Sociological Methods \& Research 43, 178-209.

Kennelly, I., Misra, J., Karides, M., 1999. The Historical Context of Gender, Race, \& Class in the Academic Labor Market. Race, Gender \& Class 6, 125-155.

Klein, D.B., Stern, C., Western, A., 2005. Political diversity in six disciplines. Academic Questions 18, 40-52. 
These are proofs of the final publication that is available at Elsevier via Poetics, doi:10.1016/j.poetic.2016.02.005,

http://www.sciencedirect.com/science/article/pii/S0304422X16000164

Knorr Cetina, K., 1999. Epistemic Cultures. How the Sciences Make Knowledge. Harvard

University Press, Harvard.

Lamont, M., 1987. How to Become a Dominant French Philosopher: The Case of Jacques Derrida. The American Journal of Sociology 93, 584-622.

Lamont, M., 2009. How Professors Think. Inside the Curious World of Academic Judgement. Harvard University Press, Cambrige, MA, London.

Lamont, M., 2012. Toward a Comparative Sociology of Valuation and Evaluation. Annual Review of Sociology 38, 201-221.

Lamont, M., Kaufman, J., Moody, M., 2000. The Best of the Brightest: Definitions of the Ideal Self Among Prize-Winning Students. Sociological Forum 15, 187-224.

Lamont, M., Molnár, V., 2002. The Study of Boundaries in the Social Sciences. Annual Review of Sociology 28, 167-195.

Lamont, M., Swidler, A., 2014. Methodological Pluralism and the Possibilities and Limits of Interviewing. Qualitative Sociology 37, 153-171.

Latour, B., 1988. The Pasteurization of France. Harvard University Press, Cambridge.

Laurison, D., Friedman, S., 2015. Introducing the Class Ceiling: Social Mobility into Britain's Elite Occupations. LSE Sociology Department Working Paper Series. LSE Academic Publishing, London.

Lee, F.S., Harley, S., 1998. Peer Review, the Research Assessment Exercise and the Demise of Non-Mainstream Economics. Capital \& Class 22, 23-51.

Lewis, L.S., 1998. Scaling the Ivory Tower: Merit and Its Limits in Academic Careers. Transaction Publishers, New Brunswick, NJ.

Long, G.L., 1987. Organizations and Identity: Obituaries 1856-1972. Social Forces 65, 9641001. 
Long, S.J., Fox, M.F., 1995. Scientific Careers: Universalism and Particularism. Annual Review of Sociology 21, 45-71.

Macfarlane, B., Chan, R.Y., 2014. The last judgement: exploring intellectual leadership in higher education through academic obituaries. Studies in Higher Education 39, 294-306.

Maeße, J., 2015. Economic Experts. A Discursive Political Economy of Economics. Journal of Multicultural Discourses 10, 279-305.

McNamee, S.J., Miller, R.K.J., 2004. The Meritocracy Myth. Rowman \& Littlefield, Langham, Md. et al.

Morgan, M., Baert, P., 2015. Conflict in the Academy. A Study in the Sociology of Intellectuals. Palgrave Pivot, Basingstoke.

Nederhof, A.J., 2006. Bibliometric Monitoring of Research Performance in the Social Sciences and the Humanities: A Review. Scientometrics 66, 81-100.

Patton, M.Q., 2002. Qualitative Research \& Evaluation Methods. SAGE, Thousand Oaks.

Popp Berman, E., 2012. Creating the Market University: How Academic Science Became an Economic Engine. Princeton University Press, Princeton.

Rodler, C., Kirchler, E., Hölzl, E., 2001. Gender Stereotypes of Leaders: An Analysis of the Contents of Obituaries from 1974 to 1998. Sex Roles 45, 827-843.

Rossiter, M.W., 1993. The Matthew Matilda Effect in Science. Social Studies of Science 23, $325-341$.

Sandström, U., Hällsten, M., 2008. Persistent nepotism in peer-review. Scientometrics 74, 175189.

Shortland, M., Yeo, R., 1996. Telling Lives in Science: Essays on Scientific Biography. Cambridge University Press, Cambridge.

Snow, C.P., 1963. The Two Cultures: And A Second Look. Cambridge University Press, Cambridge. 
Söderqvist, T., 2011. The Seven Sisters: Subgenres of Bioi of Contemporary Life Scientists. Journal of the History of Biology 2011, 633-650.

Sonnert, G., 1995. What Makes a Good Scientist? Determinants of Peer Evaluation among Biologists. Social Studies of Science 25, 35-55.

Speer, S.A., 2002. »Natural « and »contrived « data: a sustainable distinction? Discourse Studies $4,511-525$.

Strauss, A.L., Corbin, J.M., 1990. Basics of Qualitative Research. Grounded Theory Procedures and Techniques. Sage, Newbury Park.

Terrall, M., 2006. Biography as Cultural History of Science. Isis 2006, 306-313.

Tight, M., 2008. Dead academics: what can we learn about academic work and life from obituaries? London Review of Education 6, 125-135.

Tsay, A., Lamont, M., Abbott, A., Guetzkow, J., 2003. From character to intellect: changing conceptions of merit in the social sciences and humanities, 1951-1971. Poetics 2003, 2349.

Vincent, D., 1981. Bread, Knowledge and Freedom: A Study of 19th Century Working-Class Autobiography.

Wacquant, L.D., 2000. Academic Portraits: Autobiography and Scientific Censorship in American Sociology, in: Kinloch, G.C., Mohan, R.P. (Eds.), Ideology and the Social Sciences. Greenwood Press, Westport, London, pp. 147-157.

Wolf-Wenderl, L.B., Twombly, S.B., Rice, S., 2004. The Two-Body Problem. Dual-CareerCouple Hiring Practices in Higher Education. John Hopkins University Press, Baltimore, MD.

Zippel, K., 2011. How Gender Neutral are State Policies on Science and International Mobility of Academics? Sociologica 5, 1-17. 
These are proofs of the final publication that is available at Elsevier via

Poetics, doi:10.1016/j.poetic.2016.02.005,

http://www.sciencedirect.com/science/article/pii/S0304422X16000164

Zuckerman, H., Merton, R.K., 1971. Patterns of evaluation in science: Institutionalisation, structure and functions of the referee system. Minerva 9, 66-100.

Julian Hamann holds a postdoctoral position at the Forum Internationale Wissenschaft, University of Bonn, Germany. He obtained his PhD.D. in 2014 from the University of Bamberg, Germany, with a study on the notion of "Bildung" in the German humanities. From 2014 to 2015, he was Feodor Lynen postdoctoral research fellow of the Alexander von Humboldt Foundation at the University of Warwick, UK, and Northeastern University, Boston, MA, USA. His research interests involve a sociology of social sciences and humanities on the grounds of a sociology of scientific knowledge. Current projects examine non--intended effects of external research performance assessments, and dynamics of professorial appointment procedures.

\section{Footnotes}

${ }^{1}$ In this text, the term "position" is used to refer to general locations in the academic world to which academics are ascribed via positioning practices. The term "post" is used to refer to a specific job within an academic institution (e.g., assistant professor, emeritus professor).

${ }^{2}$ Cf. Speer (2002) on the fragile distinction between "natural" and "contrived" data (see also Jerolmack \& Khan, 2014; Lamont \& Swidler, 2014, for a recent debate on the implications of different data collection techniques).

${ }^{3}$ Status differences between academic biographies and obituaries are revealed by the fact that only $18 \%$ of the decedents in the focal sample of obituaries had written an autobiography or had a biography written about them. 
${ }^{4}$ The analytical framework guiding this comparison, including the distinction between certain dimensions of evaluative practices, draws on a contextual triangle of evaluation developed by Phillipa Chong and Michèle Lamont.

${ }^{5}$ Because of the particular historical development of sociology in the UK, and especially its belated institutionalization (Halsey, 2004), the limited number of obituaries available from the 1960s for British sociologists constrained the size of the subgroups.

${ }^{6}$ A complete list of the publications can be requested from the author.

${ }^{7}$ Taken together, the two narratives appear in almost $75 \%$ of all obituaries in the sample. In some cases, both are mobilized in a single obituary, but overall, depictions of natural talent and of merit are widely mutually exclusive. 